\section{Guiding Principles}

The Sub-Committee recommended that the following five principles be adhered to:

1. Access to a staff office in refugee cases must not derogate from the freedom of choice of counsel. Refugee claimants who are eligible for legal aid assistance must be entitled to choose between representation by staff counsel and representation by counsel of their own selection retained on a legal aid certificate.

2. Staff counsel must be independent in all aspects of their relationship with their client to the same extent as in a relationship between a solicitor and a legally aided client.

3. There must be assurance of necessary resources, including both sufficient resources for the full and proper preparation of each case by lawyers and paralegal staff and sufficient resources for necessary disbursements.

4. The existence of a staff office must not in any way result in less recognition by the plan and the government of the importance of continuing the private bar delivery of legal aid servicesto refugee claimants or anylesser remuneration to those lawyers in the private bar providing legal aid services to refugee claimants than to other lawyers. As part of the evaluation of the pilot project, there must be an assessment of the impact of the staff office on access to legal services in refugee law delivered by the private bar.

5. The practice of refugee law has an inherent community advocacy function that should be part of any pilot project.

The Sub-Committee recommended that the refugee pilot staff office focus primarily on representing refugee claimants at hearings before the Refugee Division of the IRB. A secondary aspect of their work would be on internally generated appellate work and test-case appellate work. The staff office should also make available through the Legal Aid

continued on page 22

\title{
Empower the Most Vulnerable: A People-Oriented Planning Workshop
}

\author{
Véronique Lassailly-Jacob
}

This workshop, sponsored by the Reconstruction and Rehabilitation ( $R$ and $R$ ) Fund of the Canadian Council for International Co-operation (CCIC), was held in Ottawa, April 19-20, 1993.

This very informative workshop conducted by Mary B. Anderson and Tim Brodhead regrouped many Canadian NGO representatives involved in refugee programs. The main target of this training session was to discuss ways of improving the efficiency and effectiveness of international assistance provided to refugees in the context of developing countries. Improving refugee programs implies using resources more efficiently, increasing the opportunities for refugees to assume responsibility for their own management and programs and ensuring that programs benefit everybody in the community-men, women, children and the most vulnerable.

The audience was introduced to two concepts presented as compulsory prerequisites of successful programs. The first concept discussed was changechange in the customary social and economic roles of each individual in a refugee context- "it is essential in planning activities for refugees that you have an in-depth understanding of the dynamics of change working within the society. These determine, to a great extent, the acceptance and success of any project." Second, the concept of refugee participation was defined as "recognizing that full participation requires the involvement of refugee women, men and children."

The ways of assessing socioeconomic changes in a refugee community as well as determining the ability of refugees to participate in and benefit from the programs was then examined. We were invited to discuss a framework

Véronique Lassailly-Jacob, from France, is a visiting research fellow at $\mathrm{CRS}$. built as an analysing tool for sociocultural and economic components in a refugee community. This three-step framework, based on a UNHCR report, 1 is conceived as " a new analytical framework which combines elements of gender analysis and capacitiesvulnerabilities analysis."

The first step focuses on the profile and context of a refugee population. Refugee workers should remember that the overall population profile has been distorted by the refugee situation and major demographic distortions must be taken into consideration when delivering programs. The second step of the framework is an Activities Analysis. "It is essential to find out what people were doing before and what they are doing or are able to do now in the refugee situation for which you are planning." The old patterns as well as the refugee situation pattern of the female/male division of social and economic roles and responsibilities should be investigated. As for the third step, it is devoted to what resources refugees controlled and used before they became refugees and what resources they control and use now: what they have lost, what they have brought with them and what they have been provided with in their refugee situation.

Finally, we were invited to test this framework on some typical refugee situation managed by the UNHCR. Discussions focused on two study cases, the Ukwimi Refugee Settlement set up in Zambia for Mozambican refugees and the repatriation of Cambodian refugees from Thailand.

As far as I am concerned, two main points were not sufficiently mentioned. The first one is related to the great amount of time required for such an indepth analysis; refugee workers are usually very busy in implementing their programs. Will they have the time for conducting this survey? The second 